\title{
BLICKDIAGNOSE-QUIZ-AUFLÖSUNG
}

\author{
Exanthem mit typischer Lokalisierung
}

\section{Hand, Fuß und Mund sind krank}

Auflösung von Seite 11.

Richtig: D) Hand-Fuß-Mund-Krankheit

_ Die Hand-Fuß-Mund-Krankheit hat Häufigkeitsgipfel im Herbst und im Frühjahr. Betroffen sind v. a. Kinder und Jugendliche. Die Viren werden als Tröpfcheninfektion, aber auch über den Stuhl weitergegeben. Als Begleitsymptome können leichtes bis mittelstarkes Fieber, Hals- und Abdominalschmerzen sowie Erbrechen, selten auch eine Tonsillitis auftreten. Bei älteren Kindern und Erwachsenen verläuft die Erkrankung oft schwach ausgeprägt oder asymptomatisch.

Für die Diagnosestellung reicht meist die Blickdiagnose. Die Therapie erfolgt symptomatisch mit schmerzstillenden Mundlösungen oder -gels. Gerbstoffe auf den Hautläsionen sollen Sekundärinfektionen durch das Kratzen vorbeugen. Wenn das Trinken wegen der schmerzhaften Mundschleimhautläsionen schwierig ist, kann ein Trinkhalm empfohlen werden. Eine weitere Therapie ist in der Regel nicht erforderlich. Es kommt praktisch immer zur Spontanheilung, wie auch bei unserem Patienten.

Im Gegensatz dazu treten bei der Dyshidrosis von Anfang an kleine, wasserklare Bläschen auf, die in aller Regel stark jucken. Von der Maul- und Klauenseuche sind primär Tiere betroffen. Nur selten infizieren sich Menschen, die dann keine oder nur geringfügige Symptome zeigen. Bei den Windpocken ist in der Regel die gesamte Körperoberfläche einschließlich der behaarten Kopfhaut vom Exanthem betroffen.

$\rightarrow$ Prof. Dr. Dr. Dr. Christoph Raschka Im Igelstück 31, D-36088 Hünfeld

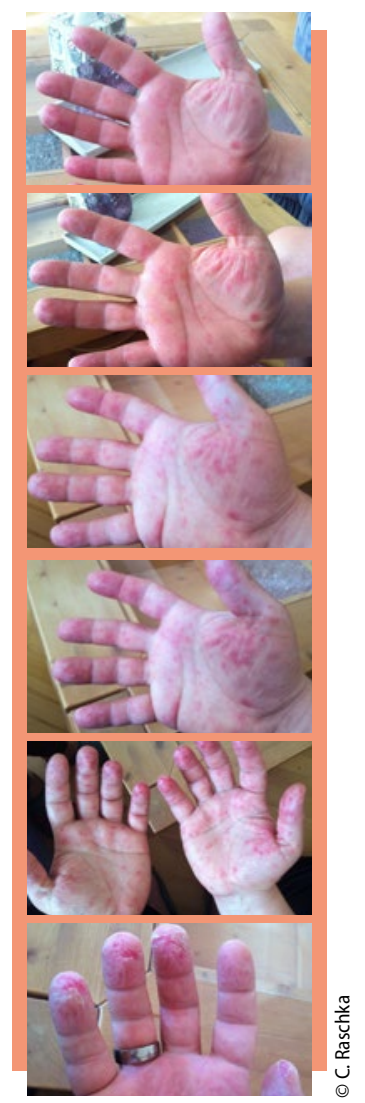

\section{Hier steht eine Anzeige.}

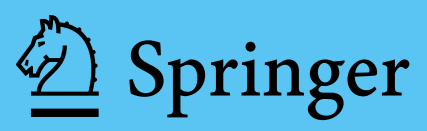

